\title{
A large-scale outbreak of hand, foot and mouth disease, France, as at 28 September 2021
}

Audrey Mirand ${ }^{1,2}$, Robert Cohen ${ }^{3}$, Maxime Bisseux ${ }^{1,2}$, Stéphanie Tomba² , Fabienne Cahn Sellem ${ }^{4}$, Nathalie Gelbert ${ }^{4}$, Stéphane Béchet $^{3}$, Bruno Frandji5 , Christine Archimbaud ${ }^{1,2}$, Amélie Brebion ${ }^{1}$, Hélène Chabrolles ${ }^{1,2}$, Christel Regagnon ${ }^{1}$, Corinne Levy ${ }^{3}$, Jean-Luc Bailly, ${ }^{1,2}$, Cécile Henquell ${ }^{1,2}$

1. CHU Clermont-Ferrand, Laboratoire de Virologie, Centre National de Référence des entérovirus et parechovirus - Laboratoire Associé, Clermont-Ferrand, France

2. Université d'Auvergne, LMGE UMR CNRS 6023 Equipe EPIE - Epidémiologie et physiopathologie des infections à entérovirus, Faculté de Médecine, Clermont-Ferrand, France

3. Association Clinique et Thérapeutique Infantile du Val de Marne (ACTIV), Créteil, France

4. Association Française de Pédiatrie Ambulatoire (AFPA), Orléans, France

5. CompuGroup Medical France, Nanterre, France

Correspondence: Audrey Mirand (amirand@chu-clermontferrand.fr)

Mirand Audrey, Cohen Robert, Bisseux Maxime, Tomba Stéphanie, Sellem Fabienne Cahn, Gelbert Nathalie, Béchet Stéphane, Frandji Bruno, Archimbaud Christine, Brebion Amélie, Chabrolles Hélène, Regagnon Christel, Levy Corinne, Bailly Jean-Luc, Henquell Cécile. A large-scale outbreak of hand, foot and mouth disease, France, as at 28 September 2021. Euro Surveill. 2021;26(43):pii=2100978. https://doi.org/10.2807/1560-7917.ES.2021.26.43.2100978

We report a large-scale outbreak of hand, foot and mouth disease (HFMD) in France. As at 28 September 2021, 3,403 cases have been reported ( $47 \%$ higher than in 2018-19). We prospectively analysed 210 clinical samples; 190 (90.5\%) were enterovirus-positive. Most children presented with atypical HFMD. Coxsackievirus (CV)A6 (49.5\%; 94/190) was predominant; no enterovirus A71 was detected. Dermatological and neurological complications of HFMD justify prospective syndromic and virological surveillance for early detection of HFMD outbreaks and identification of associated types.

Hand, foot and mouth disease (HFMD) and herpangina (HA) are childhood diseases most commonly associated with various non-polio enterovirus (EV) types. HFMD/HA are usually benign, although neurological complications are often observed during large epidemics involving EV-A71 [1-3]. On 14 June 2021, the French Paediatric and Ambulatory Research in Infectious diseases (PARI) network informed the Associated Laboratory of the National Reference Centre (AL-NRC) for enteroviruses and parechoviruses of an unusual increase in HFMD/HA cases in children observed in calendar week 24 . This alert triggered a virological investigation to detect whether the causative virus was an EV-A71 or a new EV variant. We aimed to describe the epidemiological, clinical and virological characteristics of this large-scale outbreak of HFMD/HA.

\section{Syndromic surveillance for hand, foot and mouth disease and herpangina}

Since September 2017, PARI has been conducting prospective surveillance of the most common paediatric infectious diseases seen in outpatient settings. The EV-associated mucocutaneous illnesses HFMD/HA are included in the PARI surveillance panel [4]. The PARI network includes 113 paediatricians (as at September 2021; ca $4 \%$ of all French paediatricians) located throughout all French metropolitan regions except Corsica and is coordinated by the Association Clinique et Thérapeutique du Val de Marne (ACTIV). Each paediatrician uses the same medical software (AxiSanté 5-InfanSoft, CompuGroup Medical, Nanterre, France) for patient record management. The system enables paediatricians to report cases of HFMD/HA based on diagnoses according to the International Statistical Classification of Diseases, 10th revision, including Bo8.4 (enteroviral vesicular stomatitis with exanthem), Bo8.5 (enteroviral vesicular pharyngitis), B97.1 (enterovirus as the cause of diseases classified elsewhere), and R21 (rashes and other nonspecific skin eruptions suggesting enterovirus infection) [5]. Automated data extraction from computerised medical records tracks the clinical epidemiology of HFMD/HA. A weekly newsletter reporting the number of cases or each monitored infectious disease is sent to all paediatricians and the AL-NRC by ACTIV.

A rapid increase in the number of mucocutaneous manifestations suggestive of EV infection in children was observed at week 24 in 2021 by the PARI network. The number of cases continued to increase until week 27 , during which 291 cases were recorded (Figure 1). This is 
Weekly case numbers of hand, foot and mouth disease (HFMD) and herpangina (HA) reported by the Paediatric and Ambulatory Research in Infectious diseases network, 2018-2021 $(\mathrm{n}=12,594)$ and of analysed clinical samples in children with HFMD/HA, France, $2021(n=210)$

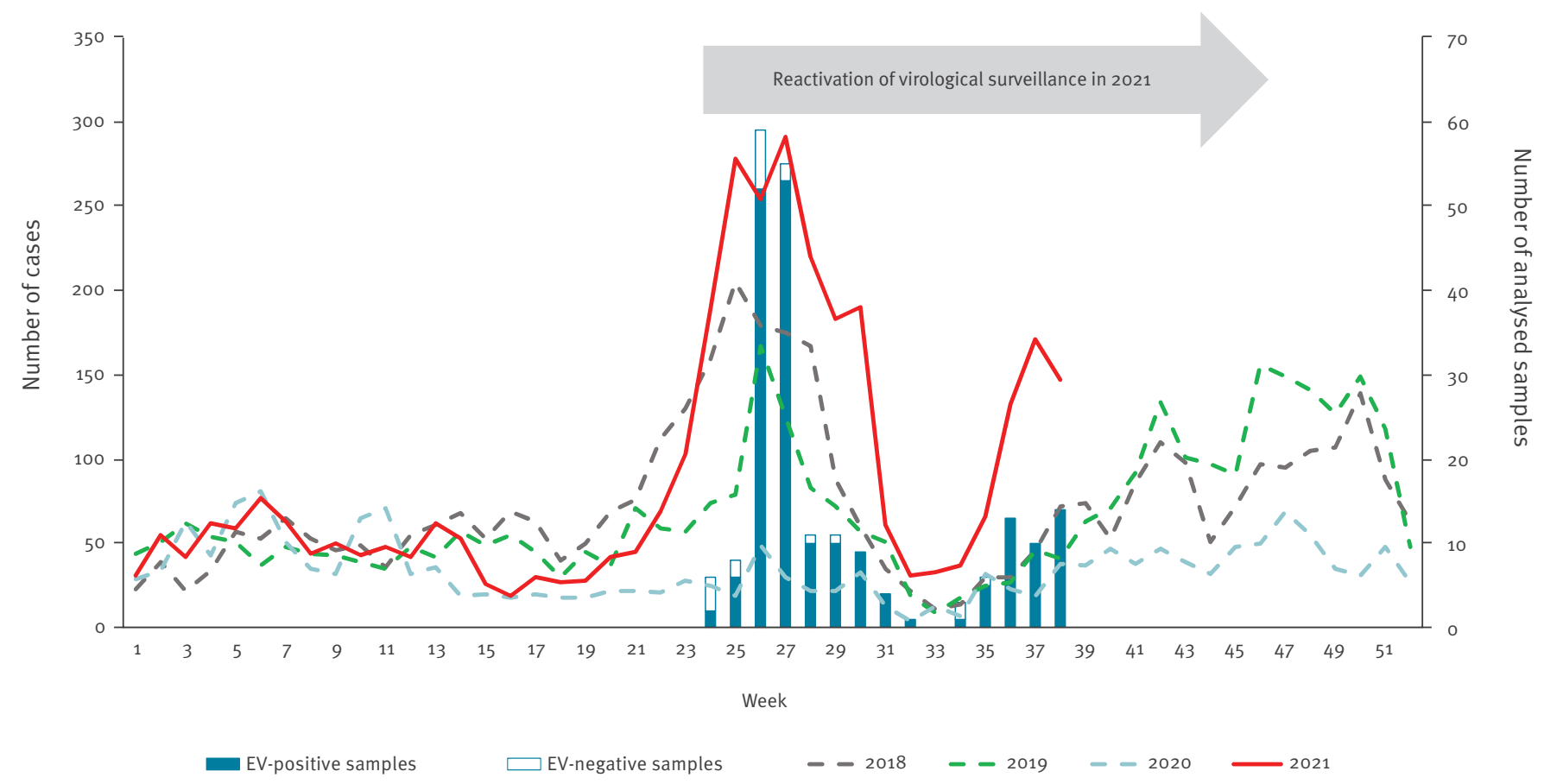

EV: enterovirus; HFMD: hand, foot and mouth disease; HA: herpangina; PARI: Paediatric and Ambulatory Research in Infectious diseases network.

Vertical bar sections represent the number of EV-positive (blue bars) and -negative samples (white bars) since the reactivation of PARI virological surveillance for HFMD/HA at week 24 in 2021.

the highest number of weekly cases reported since syndromic surveillance began in 2017. A second HFMD/HA upsurge began in week 35 and peaked in week 37. As at week 38 in 2021, 3,403 cases were reported, compared to respective case numbers in $2020(n=1,201), 2019$ $(n=1,996)$ and $2018(n=2,616)$ for the same period.

\section{Clinical and virological surveillance}

Syndromic surveillance was complemented by virological surveillance of HFMD/HA. Virological surveillance was first established in April 2014. After a suspension in 2020 because of the COVID pandemic, the surveillance was reactivated in 2021 during week 24, following the PARI network alert. Briefly, volunteer paediatricians in the PARI network collected, at discretion, throat or buccal swab specimens from children clinically diagnosed with HFMD/HA and sent samples with a standardised clinical report form to the AL-NRC for pan-EV testing (Enterovirus R-GENE, bioMérieux, Marcy-l'Étoile, France) and EV genotyping [6]. Based on the clinical items checked on the form, typical HFMD was defined by the presence of at least one typical localisation of HFMD, e.g. oral ulcerations, rash on palms, soles, buttocks, elbows or knees excluding any other site, whereas atypical HFMD was defined as HFMD with the presence of a rash at atypical sites or a generalised rash, or an atypical presentation such as
Gianotti-Crosti syndrome (including papulo-vesicular eruption on buttocks and limbs) or eczema coxsackium. Herpangina was defined as localised oral ulcerations in the posterior part of the oral cavity [6].

As at 28 September $2021,37.2 \%$ of paediatricians in the PARI network (42/113) across 10 of 13 French regions participated in clinical and virological surveillance. They prospectively sent 210 samples to the AL-NRC, which corresponded to $9.2 \%(210 / 2,283)$ of the cases reported by the PARI network between weeks 24 and 38. EV infection was confirmed in 90.5\% (190/210) of children in eight regions (Figure 2 ). The mean age was 2.09 years (range: 21 days -7.4 years); the male:female sex ratio was 1.3. Fever or history of fever was reported in $78.9 \%(150 / 190)$ of EV-infected children. Most of them presented with atypical HFMD $(64.2 \% ; 122 / 190)$ associated with $\mathrm{HA}(30.5 \% ; \mathrm{n}=58)$ or without $\mathrm{HA}$ (33.7\%; $n=64)$; typical HFMD and HA alone were observed in $20.5 \%(n=39)$ and $15.3 \%(n=29)$ patients, respectively. Neurological signs including headache $(n=8)$, irritability $(n=31)$ and drowsiness $(n=5)$ were reported in $23.2 \%$ of children $(n=44)$ (Table 1$)$.

Identification of the EV genotype was achieved for 95.8\% (182/190) samples. EV-A71 was not detected. Another EV A type was identified in $93.2 \%$ (177/190) 


\section{FIGURE 2}

Geographical distribution of the number of hand, foot and mouth disease and herpangina cases and of enteroviruspositive samples in children, France, weeks 24-38, 2021 $(\mathrm{n}=190)$

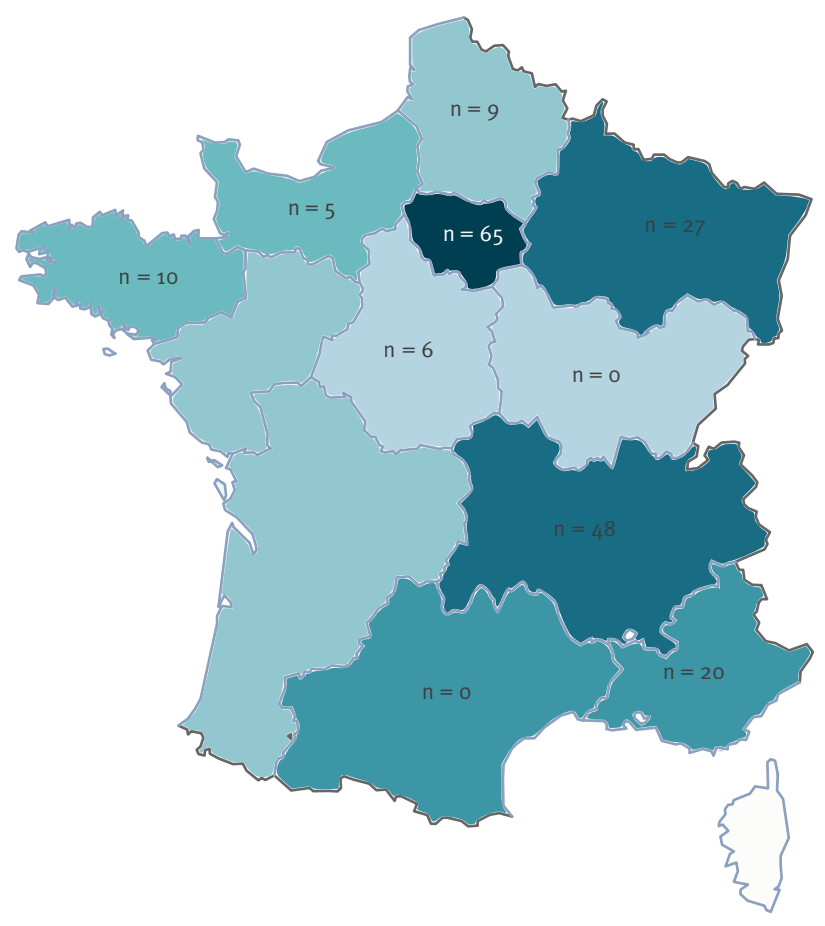

Syndromic surveillance

Hand, foot and mouth disease/herpangina cases

$$
\begin{array}{lll}
<10 & 50-99 & 200-499 \\
10-49 & 100-199 & >500
\end{array}
$$

Syndromic surveillance (colour gradient): the number of hand, foot and mouth disease and herpangina cases reported through the syndromic surveillance between weeks 24 and 38 .

Virological surveillance (n per region): In each French metropolitan region, the $n$ number indicates EV-positive samples. No samples were collected in five of the 13 regions, either because no paediatrician was involved in the virological surveillance in these regions $(n=3)$ or because no sample was collected $(n=2)$.

of children; coxsackievirus A6 (CVA6) was the most predominant type $(n=94 ; 49.5 \%)$ followed by CVA16 $(n=42 ; 22.1 \%)$ and CVA5 $(n=21 ; 11.1 \%)$ (Figure 3). CVA6 and CVA16 were mostly associated with atypical HFMD (75/94; 79.8\% and 26/42; 61.9\%, respectively) and CVA 5 was more frequently associated with herpangina alone $(11 / 21 ; 52.4 \%)$.

The phylogenetic analysis of 71 partial VP1 sequences of the 94 CVA6 strains sampled in France in 2021 showed that 69 sequences were grouped in two main distinct lineages within the genogroup $D$. The two remaining sequences were dispersed within the genogroup D. All sequences displayed close genetic relationships with viruses recovered in France in 2017-18 (Figure 4). However, whole genome analysis of viral strains is needed to determine whether the strains involved in the 2021 epidemic could represent new variant forms.
TABLE 1

Clinical features of children with enterovirus infections associated with hand, foot and mouth disease and herpangina, France, weeks 24-38 $(\mathrm{n}=190)$

\begin{tabular}{|c|c|c|}
\hline \multirow[t]{2}{*}{ Clinical characteristics } & \multicolumn{2}{|c|}{$\begin{array}{c}\text { EV-infected childrena } \\
\qquad(n=190)\end{array}$} \\
\hline & $\mathrm{n}$ & $\%$ \\
\hline \multicolumn{3}{|l|}{ General signs of illness } \\
\hline Fever or history of fever & 150 & 78.9 \\
\hline Asthenia & 55 & 28.9 \\
\hline \multicolumn{3}{|l|}{ Localisations of eruptions } \\
\hline Palms & 100 & 52.6 \\
\hline Soles & 104 & 54.7 \\
\hline Buttocks & 98 & 51.6 \\
\hline Elbows/knees & 50 & 26.3 \\
\hline Lower limbs & 58 & 30.5 \\
\hline Upper limbs & 45 & 23.7 \\
\hline Generalised eruption & 14 & 7.4 \\
\hline Trunk & 22 & 11.6 \\
\hline Face & 68 & 35.8 \\
\hline Giannotti-Crosti syndrome $^{\mathrm{b}}$ & 12 & 6.3 \\
\hline Eczema coxsackium & 11 & 5.8 \\
\hline \multicolumn{3}{|l|}{ Diagnosis } \\
\hline Typical HFMD \pm HA & 39 & 20.5 \\
\hline Atypical HFMD $\pm \mathrm{HA}$ & 122 & 64.2 \\
\hline HA alone & 29 & 15.3 \\
\hline \multicolumn{3}{|l|}{ Other signs of illness } \\
\hline Digestive & 64 & 33.7 \\
\hline Respiratory & 80 & 42.1 \\
\hline Ear, nose, throat & 56 & 29.5 \\
\hline Neurological & 44 & 23.2 \\
\hline
\end{tabular}

EV: enterovirus; HFMD: hand, foot and mouth disease; HA: herpangina.

a Children with a laboratory-confirmed EV infection.

b Giannotti-Crosti syndrome symptoms includes papulo-vesicular eruption on buttocks, face and limbs. The trunk, palms and soles are usually not affected.

Partial VP1 sequences were deposited in GenBank (accession numbers: OK635614 to OK635790).

\section{Ethical statement}

Informed consent was obtained from all parents or guardians of children. The syndromic surveillance was approved by the ethical committee of $\mathrm{CHI}$ Créteil Hospital, France [4]. The virological surveillance was approved by the review committee of the University Hospital of Clermont-Ferrand, France (reference AU1098).

\section{Discussion}

The PARI network revealed a large-scale outbreak of $\mathrm{HFMD} / \mathrm{HA}$ in France in 2021. The number of cases was $47 \%$ higher than in years 2018-19 during the same time period. Virological surveillance from week 24 showed that this epidemic was mainly associated with the CVA6 type. The biannual pattern in summer and autumn was 


\section{FIGURE 3}

Distribution of enterovirus types associated with hand, foot and mouth disease and herpangina in children, France, weeks 24-38, $2021(\mathrm{n}=190)$

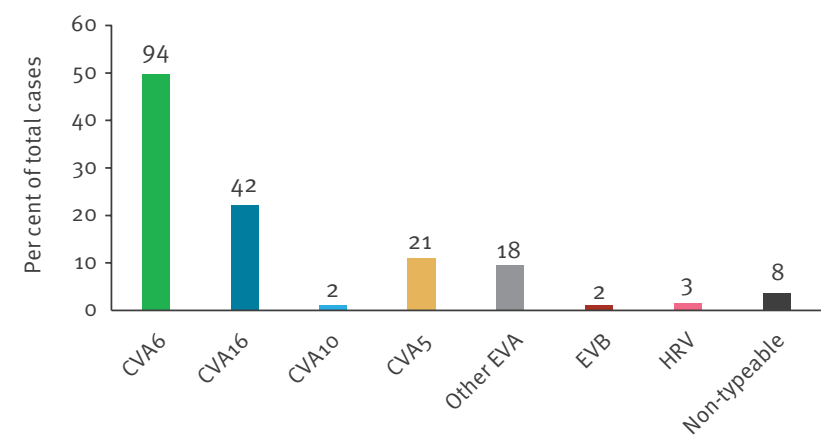

CV: coxsackievirus; EV: enterovirus; HRV: human rhinovirus.

Virological surveillance of enterovirus types from 8 French regions was performed. The $\mathrm{n}$ number above each bar indicates the number of each type from 190 EV-positive samples in children.

similar to that usually expected for these diseases in Europe or Asia $[2,4,7]$. However, the 2021 epidemic was characterised by a sharp rise in the summer and an earlier autumn peak compared with previous years. This pattern may reflect that a higher proportion of children was susceptible to viral infections including EV. The year 2020 was, in fact, marked by a very low circulation of EV, both among hospitalised patients [8] and among children seen in primary care. In response to the COVID-19 pandemic, hygiene reinforcement may have reduced infectious contacts and immune stimulation, consequently leading to a greater susceptibility to infections in children [9]. A similar phenomenon was illustrated by the recently reported outbreak of respiratory syncytial virus (RSV) infections in Japan in July 2021 [10], which was substantially larger and earlier compared with previous years. The same situation could be observed in Europe for RSV infections [11].

In our study, we did not observe a shift in the age of disease onset; the mean age of children with HFMD/ HA was similar to that of children in the 2014 epidemic (2.09 vs 2.10 years) [6]. Although we have not yet found available epidemiological data worldwide on HFMD/HA for the year 2021, it seems unlikely that the epidemic is limited to France. Signals of an HFMD/HA outbreak may have been missed elsewhere in Europe because most existing surveillance systems are hospital-based and focus on neurological EV infections [12].

We found that nearly two thirds of the children with confirmed EV-associated HFMD/HA in our study presented with atypical disease, a proportion usually observed in epidemics associated with CVA6 $[6,13]$. Since its re-emergence in 2008 , this type has been commonly associated with atypical forms of the disease $[6,13]$,

\section{FIGURE 4}

Phylogenetic tree of coxsackievirus A6 sequences from virological surveillance of hand, foot and mouth disease and herpangina in children, France, weeks 24-38, 2021 $(\mathrm{n}=71)$

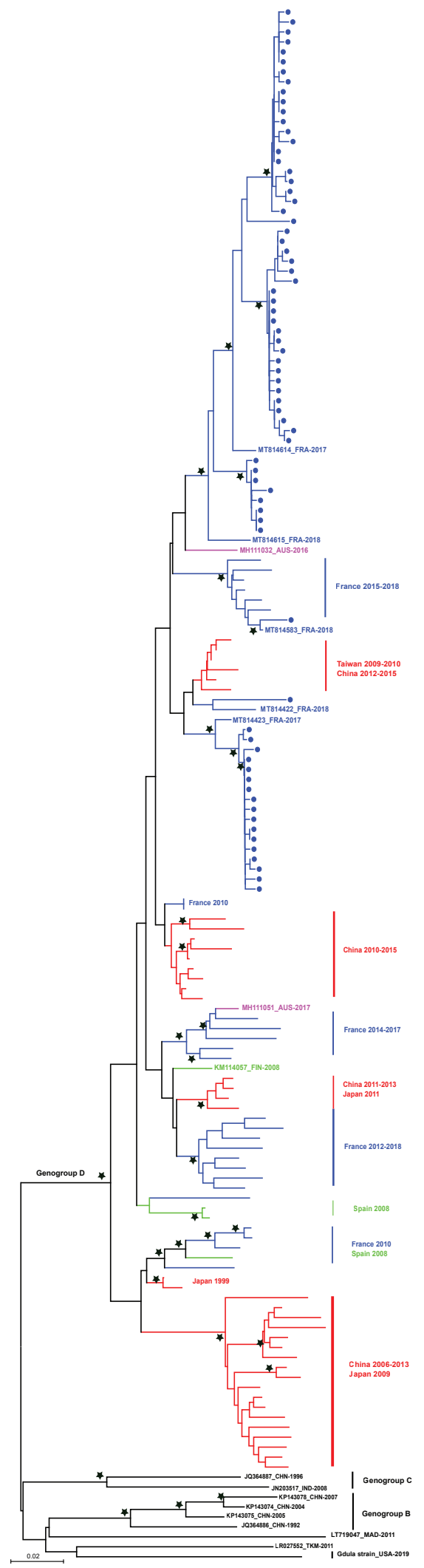

The phylogenetic tree was constructed by the neighbour-joining method and evaluated with 1,000 bootstrap pseudoreplicates, using Molecular Evolutionary Genetics Analysis (MEGA) version 6.0 software [19]. Only bootstrap values $270 \%$ are indicated by a black star. Genetic distances were calculated with Tamura-Nei's model of evolution and branch length is drawn to the indicated scale the $1 D$ gene of the Gdula prototype strain. The analysis was performed with 71 partial 1 relative to of 94 CVA6 strains. The remaining 23 sequences were less than 495 bp long. Taxon names of all sequences are provided in Supplement. The strains collected in 2021 are labelled with a filled circle. Geographical origin and time of isolation of strains are indicated by the ISO-code abbreviation followed by the year of isolation. Genogroups were designed as previously described [20]. 
sometimes affecting the whole body or associated with late-onset symptoms such as onychomadesis [14]. In addition, CVA16 was more frequently associated with atypical disease forms in 2021 than in 2014 (61.9\%; $n=26 / 42$ vs $34.1 \% ; n=42 / 123$ ) [6]. Moreover, while paediatricians are very familiar with $\mathrm{HMFD} / \mathrm{HA}$, other clinicians should also be aware of these diseases, as they are not uncommon in adults living with children. In a CVA6-associated outbreak described in Finland in 2008 , one third of the patients with HFMD/HA were adults [15]. As in children, presentation of the disease in adults can be atypical, which can make the diagnosis difficult and, in some cases, lead to hospitalisation [16].

In our primary care-based study, no data on hospitalisation were collected. As some HFMD/HA cases may be complicated by extensive skin manifestations or severe neurological conditions, this information would be valuable, as it could allow the close monitoring of hospitalised cases of HFMD/HA to detect a change in the clinical presentation or in the frequency of complications associated with these diseases. Data on hospitalised cases of HFMD/HA could be collected through hospital-based surveillance of EV infections as proposed by the European Non-Poliovirus Enterovirus Network (ENPEN), which has established standardised protocols for surveillance for HFMD, respiratory and neurological infections caused by EV and parechoviruses [17]. In France, no increase in the number of hospitalised cases of HFMD/HA has been observed through the EV hospital-based surveillance [8].

\section{Conclusions}

The widespread circulation of non-polio EV, the epidemic pattern of EV infections and the recent emergence of EV-D68 and EV-A71 involved in severe neurological conditions warrant reinforcement of the surveillance of EV infections [18]. The PARI ambulatory syndromic surveillance proved to be effective for the early tracking of the 2021 outbreak. Detection of future HFMD/HA outbreaks caused by EV-A71 or an emergent EV could be achieved in combination with virological investigations. This study shows that a paediatric ambulatory network is of value for timely detection of diseases mostly seen within primary care settings.

\section{Acknowledgements}

We thank Adeline Duard and Nathalie Rodde for excellent technical assistance for EV genome detection and genotyping. The authors are grateful to the investigators of the Paediatric and Ambulatory Research in Infectious diseases (PARI) study Network: Drs. Akou'Ou M., Andre J., Ansoborlo S., Auvrignon A., Bakhache P., Barrois S., Bastero R., Batard C., Bazouzi S., Beaussac B., Bellemin K., Benani M., Berquier J., Blanc B., Blanc J., Bled J., Bordes C., Boulanger S., Brancato S., Burtscher A., Cambier Nappo E., Cahn-Sellem F., Chartier Albrech C., Chatue Kamga H., Cheve A., Condor R., Cornic M., Coudy C., Courtot H., D Acremont G., Dagrenat V., Dauriac A., De Brito B., Deberdt P., Defives I., Delavie N., Delaygue C., Delobbe J., Delvaux S., Desandes R., Desvignes V., Devulder C., D’ovidion N., Dubreuil B., Duchene S.,
Durantel B., Elbez A., Gebhard F., Gelbert N., Givois A., Gorde-Grosjean S., Goulamhoussen S., Grue P., Gruniaux Wild É., Guiheneuf C., Hassid F., Hautefeuille C., Hennequin S., Hourlier D., Hubinois S., Issert É., Joseph M-G., Jouty C., Kampf Maupu F., Kherbaoui L., Kochert F., Koskas M., Lambert A-L., Langlais S., Le Gac I., Le Mouel F., Lecaillier F., Legras C., Lemaitre C., Lemarie D., Lienhardt J., Loe-Loumou C., Louvel M., Lubelski P., Masse M., Mawas C., Mercier An., Mercier Ag., Mercier-Oger M-O., Michot-Cottias A., Milliard D., Mindreau M., Minette D., Moore-Wipf S., Nold B., Pallard-Duhaut C., Pflieger H., Philippe F., Picard K., Pinard O., Piegay Broglia I., Pincant B., Plouhinec C., Pressac I., Pruvost Dussart I., Ravilly S., Roques G., Salaun J., Salomez S., Salinier C., Sangenis M., Sarreau C., Sartelet I., Savajols E., Schlemmer C., Sellam A., Seror E., Streicher M., Thiebault G., Thollot F., Tizi Oualou L., Traimond N., Vernoux S., Vie Le Sage F., Vigreux J., Virey B., Werner A., Wollner A., Zouari M. The paediatricians who also participated in the virological surveillance are underlined.

Funding statement: Syndromic surveillance: The PARI network is supported financially by ACTIV and received unrestricted grants from GSK, MSD vaccins, Pfizer, and Sanofi. Virological surveillance: The Centre National de Référence des Enterovirus-Parechovirus is supported by an annual grant from the French national public health network (Santé publique France).

\section{Conflict of interest}

None declared. The funders had no role in the design, execution, interpretation or writing of the study.

\section{Authors' contributions}

$A M$, JLB and $C H$ were involved in the study design of the virological surveillance. $C A, A B, H C, C R$ participated in the clinical sample analyses. MB and ST were involved in the sequencing analyses. RC, FCS, NG, SB, CL and BF coordinated the PARI network and the data collection of the syndromic surveillance. AM coordinated the data collection and analysis, as well as the drafting of the manuscript. All authors contributed to the manuscript and approved the final version.

\section{References}

1. Solomon T, Lewthwaite P, Perera D, Cardosa MJ, McMinn P, Ooi MH. Virology, epidemiology, pathogenesis, and control of enterovirus 71. Lancet Infect Dis. 2010;10(11):778-90, https:// doi.org/10.1016/S1473-3099(10)70194-8 PMID: 20961813

2. Xing W, Liao Q, Viboud C, Zhang J, Sun J, Wu JT, et al. Hand, foot, and mouth disease in China, 2008-12: an epidemiological study. Lancet Infect Dis. 2014;14(4):308-18. https://doi. org/10.1016/S1473-3099(13)70342-6 PMID: 24485991

3. Antona D, Kossorotoff M, Schuffenecker I, Mirand A, Leruez Ville $M$, Bassi C, et al. Severe paediatric conditions linked with EV-A71 and EV-D68, France, May to October 2016. Euro Surveill. 2016;21(46):30402. https://doi.org/10.2807/15607917.ES.2016.21.46.30402 PMID: 27918268

4. Cohen R, Béchet S, Gelbert N, Frandji B, Vié Le Sage F, Thiebault G, et al. New approach to the surveillance of Pediatric infectious diseases from ambulatory pediatricians in the digital era. Pediatr Infect Dis J. 2021;40(7):674-80. https:// doi.org/10.1097/INF.0000000000003116 PMID: 33657594

5. World Health Organization (WHO). International statistical classification of diseases and related health problems, 10th revision, fifth edition, 2016. Geneva: WHO; 2015. Available from: https://apps.who.int/iris/handle/10665/246208

6. Mirand A, le Sage FV, Pereira B, Cohen R, Levy C, Archimbaud $C$, et al. Ambulatory pediatric surveillance of hand, foot and mouth disease as signal of an outbreak of coxsakievirus A6 infections, France, 2014-2015. Emerg Infect Dis. 2016;22(11):1884-93. https://doi.org/10.3201/eid2211.160590 PMID: 27767012 
7. Koh WM, Bogich T, Siegel K, Jin J, Chong EY, Tan CY, et al. The epidemiology of hand, foot and mouth disease in Asia: a systematic review and analysis. Pediatr Infect Dis J. 2016;35(10):e285-300. https://doi.org/10.1097/ INF.0000000000001242 PMID: 27273688

8. Centre National de Référence des entérovirus et parechovirus. Rapport d'activités 2019-2020. [Activity report 2019-2020]. Clermont-Ferrand: CHU Clermont-Ferrand. [Accessed: $6 \mathrm{Oct}$ 2021]. French. Available from: http://cnr.chu-clermontferrand. $\mathrm{fr} / \mathrm{CNR}$

9. Cohen R, Ashman M, Taha MK, Varon E, Angoulvant F, Lévy $C$, et al. Pediatric Infectious Disease Group (GPIP) position paper on the immune debt of the COVID-19 pandemic in childhood, how can we fill the immunity gap? Infect Dis Now. 2021;51(5):418-23. https://doi.org/10.1016/j. idnow.2021.05.004 PMID: 33991720

10. Ujiie M, Tsuzuki S, Nakamoto T, Iwamoto N. Resurgence of respiratory syncytial virus infections during COVID-19 pandemic, Tokyo, Japan. Emerg Infect Dis. 2021;27(11):2969-70. https://doi.org/10.3201/eid2711.211565 PMID: 34388086

11. van Summeren J, Meijer A, Aspelund G, Casalegno JS, Erna G, Hoang $U$, et al. Low levels of respiratory syncytial virus activity in Europe during the $2020 / 21$ season: what can we expect in the coming summer and autumn/winter? Euro Surveill. 2021;26(29):2100639. https://doi.org/10.2807/1560-7917. ES.2021.26.29.2100639 PMID: 34296672

12. Harvala H, Jasir A, Penttinen P, Pastore Celentano L, Greco D, Broberg E. Surveillance and laboratory detection for non-polio enteroviruses in the European Union/European Economic Area, 2016. Euro Surveill. 2017;22(45). https:// doi.org/10.2807/1560-7917.ES.2017.22.45.16-00807 PMID: 29162204

13. Huang WC, Huang LM, Lu CY, Cheng AL, Chang LY. Atypical hand-foot-mouth disease in children: a hospital-based prospective cohort study. Virol J. 2013;10(1):209. https://doi. org/10.1186/1743-422X-10-209 PMID: 23800163

14. Mathes EF, Oza V, Frieden IJ, Cordoro KM, Yagi S, Howard R, et al. "Eczema coxsackium" and unusual cutaneous findings in an enterovirus outbreak. Pediatrics. 2013;132(1):e149-57. https:// doi.org/10.1542/peds.2012-3175 PMID: 23776120

15. Blomqvist $S$, Klemola $P$, Kaijalainen $S$, Paananen A, Simonen ML, Vuorinen T, et al. Co-circulation of coxsackieviruses A6 and $A 10$ in hand, foot and mouth disease outbreak in Finland. J Clin Virol. 2010;48(1):49-54. https://doi.org/10.1016/j. jcv.2010.02.002 PMID: 20189452

16. Ben-Chetrit E, Wiener-Well Y, Shulman LM, Cohen MJ, Elinav H, Sofer D, et al. Coxsackievirus A6-related hand foot and mouth disease: skin manifestations in a cluster of adult patients. J Clin Virol. 2014;59(3):201-3. https://doi.org/10.1016/j. jcv.2013.12.012 PMID: 24457116

17. Harvala H, Benschop KSM, Berginc N, Midgley S, Wolthers $\mathrm{K}$, Simmonds P, et al. European non-polio enterovirus network: introduction of hospital-based surveillance network to understand the true disease burden of nonpolio enterovirus and parechovirus infections in Europe. Microorganisms. 2021;9(9):1827. https://doi.org/10.3390/ microorganisms9091827 PMID: 34576722

18. Fischer TK, Simmonds $P$, Harvala $H$. The importance of enterovirus surveillance in a post-polio world. Lancet Infect Dis. 2021;S1473-3099(20):30852-5. https://doi.org/10.1016/ S1473-3099(20)30852-5 PMID: 34265258

19. Tamura K, Stecher G, Peterson D, Filipski A, Kumar S. MEGA6: Molecular Evolutionary Genetics Analysis version 6.0. Mol Biol Evol. 2013;30(12):2725-9. https://doi.org/10.1093/molbev/ mst197 PMID: 24132122

20. Song Y, Zhang Y, Ji T, Gu X, Yang Q, Zhu S, et al. Persistent circulation of Coxsackievirus $A_{6}$ of genotype $D_{3}$ in mainland of China between 2008 and 2015. Sci Rep. 2017;7(1):5491. https://doi.org/10.1038/s41598-017-05618-o PMID: 28710474

\section{License, supplementary material and copyright}

This is an open-access article distributed under the terms of the Creative Commons Attribution (CC BY 4.0) Licence. You may share and adapt the material, but must give appropriate credit to the source, provide a link to the licence and indicate if changes were made.

Any supplementary material referenced in the article can be found in the online version.
This article is copyright of the authors or their affiliated institutions, 2021. 